\title{
Evaluation of Inventory Management Systems of the Nigeria Production Industries
}

\author{
Buliaminu Kareem ${ }^{1}$ \\ ${ }^{I}$ (Department of Mechanical Engineering, Federal University of Technology, Akure, Nigeria)
}

\begin{abstract}
Many inventory problems in the previous studies were addressed theoretically. In this study practical evaluation of the inventory performance in the Nigerian industries was carried out. First, the identified industries were grouped into three categories-small-, medium- and large-scale to determine their response to the practice of inventory management based on the capital outlay. Second, the effects of the capital outlay on inventorying the salient production factors including manpower, raw material and finished goods were determined. Third, other inventorying sub-factors such as order time, lot size, cost of order, number of order, demand and production rate were also assessed. Lastly, descriptive statistical analysis was utilized in analyzing the surveyed data. The results of the study practically indicated that the inventory management (of the production staffers, raw material and finished products) was affected by the sizes of industry; small-, medium-, and large- scale. The finding has advised individual industry to develop its inventory system based on its funding capability.
\end{abstract}

Keywords: - Funding, Inventory, Management, Industries, performance

\section{INTRODUCTION}

It is essential for the organization to hold adequate stocks to minimize cost and at the same time wins customers' satisfaction. Materials contribute a major recurring investment and modern management has recognized that a constant review of inventory can reduce this capital tied up without hampering the cost and customers goodwill. The type of inventory system to be practiced in any organization depending on many factors among which are economy stability of the place, infrastructural facilities available, transportation network and many more which are called constraints. Inventory planning means the determination of the type and quantity of inventory items that would be needed at future point for maintaining the production schedules $[1,2]$.

Serious effort has been made to review various definitions as regard inventory system control. For example, John [3] defined inventory control as quantitative and monetary values of items at predetermined level low within stated limit, while Levis [4] and George [5] defined it as a scientific act of controlling the amount of stock level held in various firms within a business to meet economically the intervals and external demand priced upon that business.

However many efforts at improving inventory management of the organization are evident in literature. Some of these efforts optimized inventory management using dynamic programming [6] and integer programming [7]. Many concepts have been introduced into the existing inventory models such as systems or "can-order" system (ScS) [8], larger problems Lipscitz optimization [9]. Improvement on the work of Balintfy [8] has been done by Silver [9] and Ignall [10] to make the inventory results more reliable and accurate. Periodic replenishment models proposed by Goyal [7] allow all items or specific subsets of items to be ordered in every replenishment opportunity but not beyond a base stock level. Many of these works in literature cannot fit in term of application in Industries, especially in developing country because of the gigantic and complex nature of the model developed. Besides many industries in developing countries are likely unaware of global development in inventory management [11]. Therefore, the first stage in inventory research especially in the developing countries is to assess the level of awareness and involvement in inventory managements in such regions. This will serve as indicator of how, when and where to start implementing inventory models so far developed in literature concerning single and multiple items [12], cost economy [13,14], items demand and supply forecast [15], and deterministic and stochastic systems $[16,17,18]$ inventory problems.

Many of the models developed in the past on inventory management are complex and they are very difficult to practice under unstable challenges of the developing economy. Instead, practical implementation of inventory systems in term of measure of participatory level of Nigeria industries in inventory management (in the areas of staffing, raw material procurement, and finished goods) based on the financial scale they find themselves becomes desirable. That is the aim of this study. 


\section{MATERIALS AND METHODS}

Date on inventory management systems were collected using questionnaire and oral interview of the managements of selected industries in Ondo and Lagos States of Nigeria. The companies were selected based on factors such as workers population, type of industries and location of industries. Based on stated criteria, twelve (12) industries were successfully selected and among them (in coded form) are WE Limited, AT Industry, BI Limited, TI limited, DN limited, ON Industry (all in Akure, Ondo state) and DWA limited, and CM Limited (in Lagos.). These industries, based on the stated criteria, were grouped into small-, medium- and large-scale. The names of industries are concealed to safeguard their integrity and information. The selected companies were cooperative in realizing required information as regards inventory information as well as other operational details. In these industries the following inventory management related questions were asked:

- Organization status: (public or private).

- Type of industries (small, medium-large scale)

- Labour force

- Inventory system/management (practiced or not)

- Type of inventory systems practiced

- Supply of raw materials (tons)

- Order of raw materials (practice or cost)

- How often the order is placed

- Cost of placing an order

- Problems often encountered while placing an order (transportation, political and security).

- Problems often encountered while receiving an order.

- Demand rate of finished product.

- Production rate of finished product.

The responses to various options of the above inventory related problems are sub-grouped under organisation status, industry type, labour force, inventory system and type, raw material supply, raw material quantity order, how often order is placed and its associated costs, ordering and receiving problems as well as demand and supply rates of finished goods. The system was analysed statistically using simple average to facilitate quick understanding by the practitioners. The frequency and its respective percentages for each option considered were calculated and the values obtained though the calculations are illustrated in histograms.

The statistics used is

Percentage response $(\mathrm{PR} \%)=($ Number of response/Total expected response $) \times 100$

\section{RESULTS AND DISCUSSIONS}

The results obtained for organisation status, industry type, labour force, inventory system and type, raw material supply, raw material quantity order, how often order is placed and its associated costs, ordering and receiving problems as well as demand and supply rates of finished goods are presented in Figures 1-13. Figure 1 shows that most of the industries in Nigeria are owned, managed and controlled by private individuals. The capital for running these industries is provided by private and corporate individuals of the society. The high percentage of private organization status in Nigeria is a sign that in the nearest future Nigeria will no longer practice mixed economy system of government but capitalist system of government. Implication of outcome is that the inventory management based on just-in-time practice would provide a sustainable productivity in Nigerian industries in future.

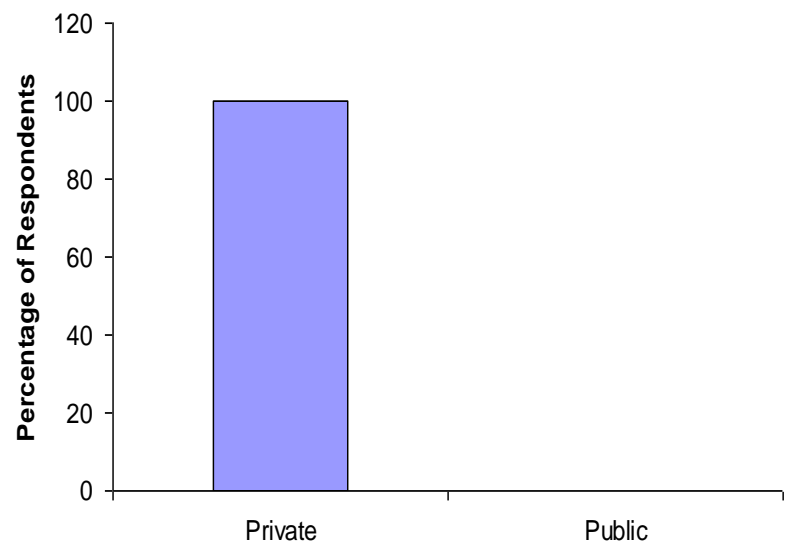

Fig 1: Chart for organization status 
From survey analysis as regard the type of industries available in Nigeria; it was discovered that about $8.33 \%$ of Nigerian industries are in small scale category. There are so many medium scale industries in Nigeria that are privately owned while about $33.33 \%$ of the industries visited were in large scale category. The percentage frequency of medium scale industry in Nigeria is $50 \%$ and the advantage of this is that it will greatly increase manpower and economy of Nigeria through employment generation for Nigerian indigenes (Figure 2). This result is an efficacy of preparedness of industrialist in facing the challenge of middle manpower shortage in the nearest future. Conventional practice of inventory management would assist to plan for number of engineers, technologists, and technicians that would be required from the Nigerian educational institutions for future industrial sustainability.

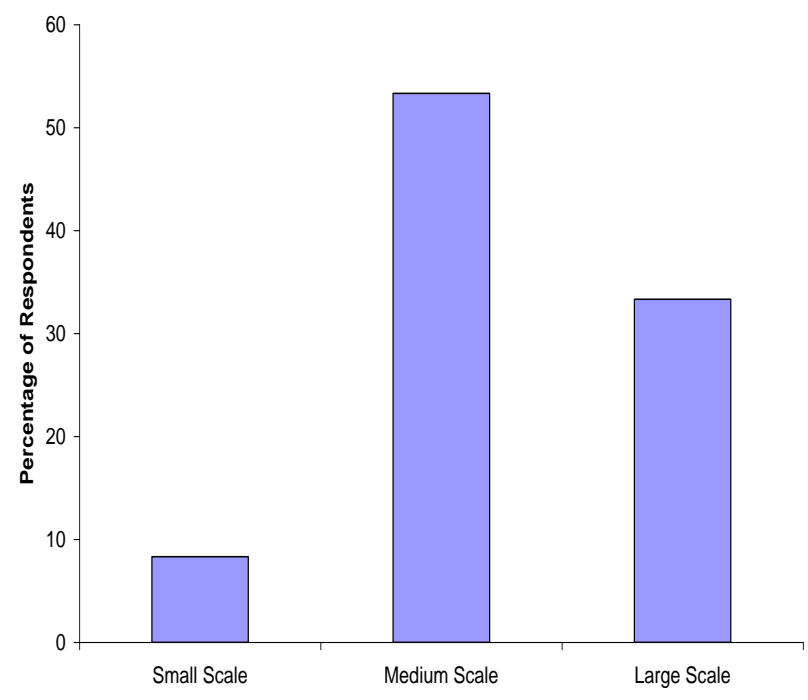

Fig 2: Chart for type of industry

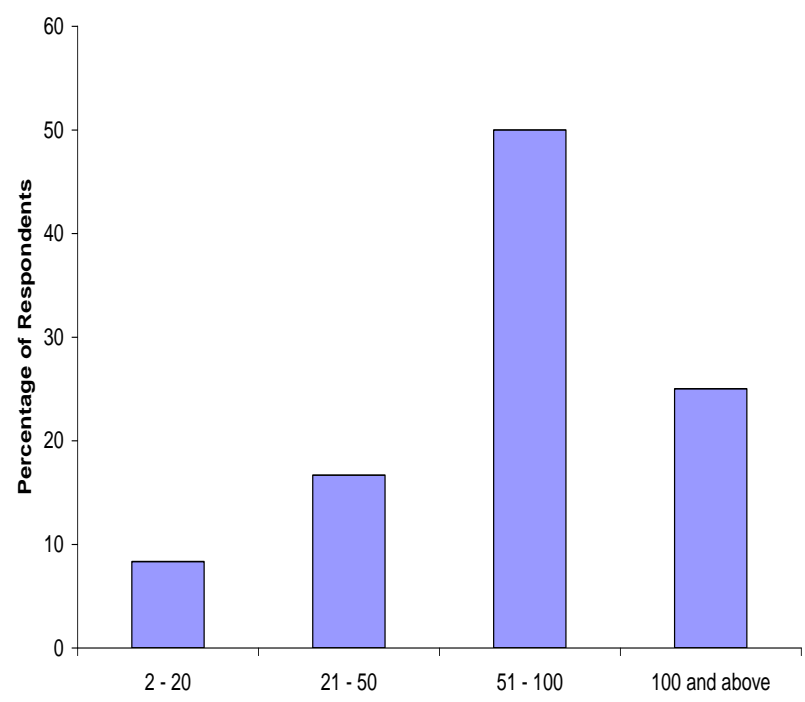

Fig 3: Chart for labour force

Figure 3 shows that $50 \%$ of Nigerian industries are having 51 to 100 staff both skilled and unskilled labour as the total number of workers contributing to manpower development of the industries. This is quiet impressive. Only $25 \%$ of the industries also are having over 100 staff. Likewise $8.33 \%$ of the industries are having number of workers ranging between 2 to 20. This is attributed to small scale nature of industries. This shows that more efforts in the area of inventorying expatriates through collaboration of industries with Universities and research institutes would enhance improved productivity of the industries. Besides, upgrade of the numerous medium scale industries to the status of large-scale would be enhanced by the expatriates.

Larger percentage of Nigerian industries keep inventory of their goods and this will greatly improve the goods and services rendering by these industries. Surveys showed that $91.6 \%$ of Nigerian industries practiced inventory system while just $8.33 \%$ of the industries are yet to know the advantages attributed to keeping 
inventory system (Figure 4). This indicates that inventory management has been in existence in the industries in the past. Only the effectiveness and understanding of the practice may be questionable.

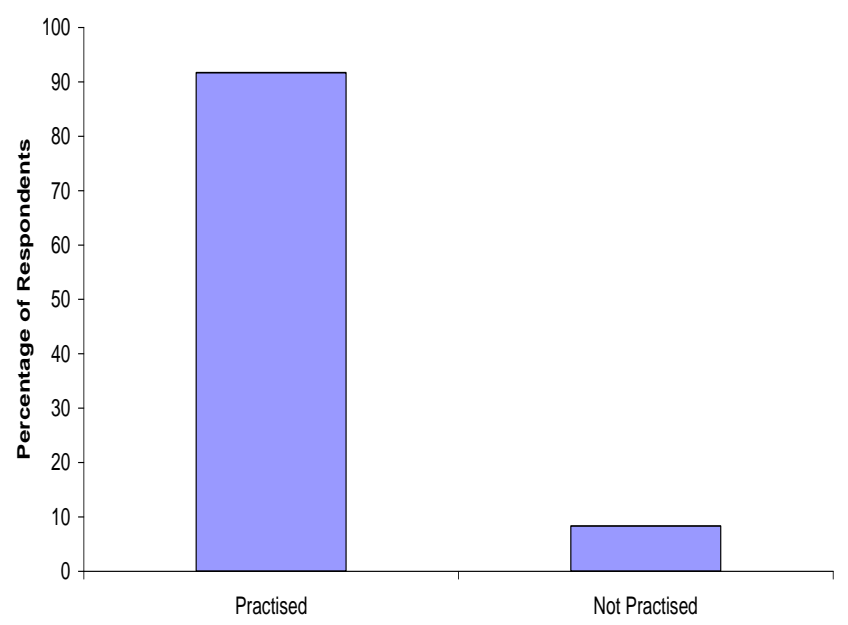

Fig 4: Chart for inventory system

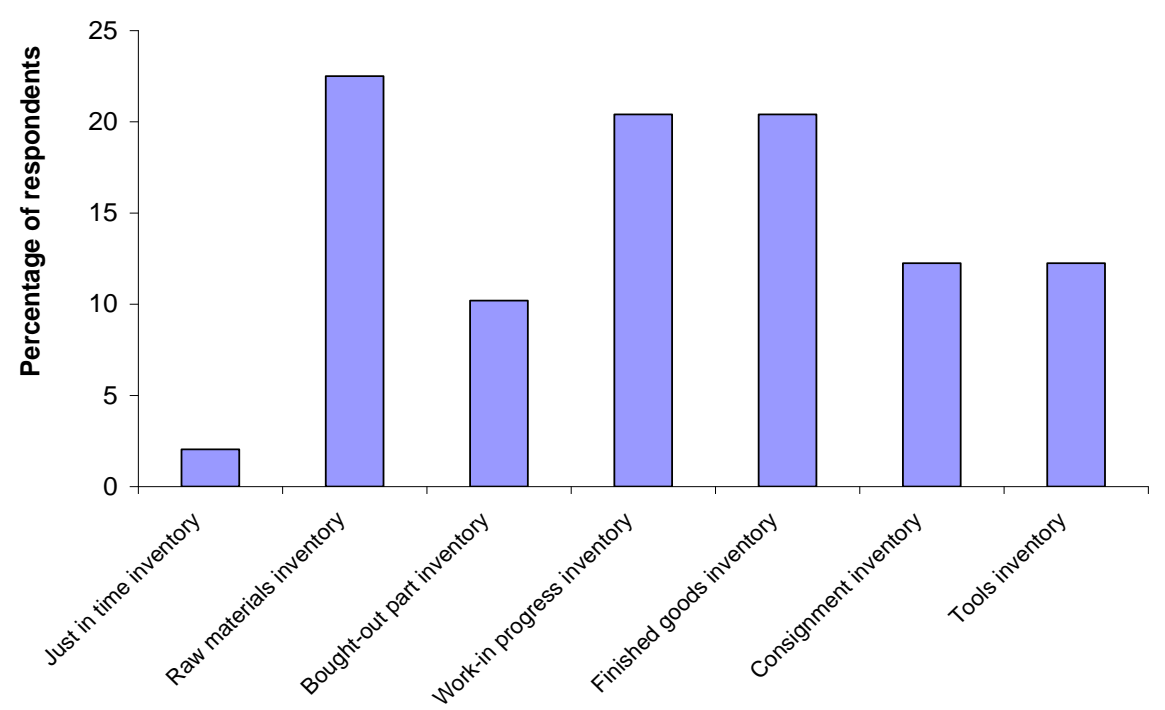

Fig 5: Chart for type of inventory system

The results show that raw materials inventory is very important to keep in the industries (Figure 5). Infact, the percentage frequency of the raw materials in the Figure 6 is very high because of its importance. This shows that basic non-fabricated materials which have not undergone any operation since they were received from suppliers have to be kept in record so that the work flows into and out of any industries can be monitored and be determined easily to safeguard any shortage. If any shortage of raw material is envisaged back-order arrangement must be made. It is a known fact from this study that just- in- time inventory system is scantly practiced in Nigerian industries. The low percentage $2.04 \%$ ) of just-in-time inventory system in Nigerian industries can be traced to some factors such as irregular lead-time from suppliers and transportation or road network problem.

About $83.33 \%$ of the industries visited have more than five (5) suppliers of raw materials (Figure 6). By doing this, there will be competitions among the suppliers and none of them will be willing to render poor service since there are others who can render excellent services to the concerned industries. This will greatly increase the productivity of the industries. By having more than five suppliers of the same raw materials is a good method of assessing the quality of services rendered by each supplier. About $16.67 \%$ of industries in Nigeria have just 2 to 5 suppliers of raw materials but, it will be better to have at least more than 5 suppliers of 
raw materials in future so that industries can easily assess quality of service rendering by each of suppliers (Figure 7). Most of the industries in Nigeria are placing order for raw materials from suppliers who are diligent in their service and faithful to them in supplying whatever they ordered. This is very good (Figure 8). There are many costs associated with placing and receiving an order. For the sake of this work, clerical and administration cost, transportation cost, postage cost, accounting cost and inspection cost were considered. Among these costs, Figure 9 shows that $26.83 \%$ of Nigerian industries give room for transportation cost while placing and receiving order. For clerical and administration cost, $21.95 \%$ of the industries in Nigeria considered this while placing and receiving order and for both inspection and postage cost, these costs affect $19.51 \%$ of the industries.

There are some problems attached to placing an order. Some of these problems are transportation, political and security. Among these challenges, transportation is the most critical and it affects about $64.29 \%$ of Nigerian industries. This is due to poor transportation system, poor road network, and paucity of vehicular spare parts. Figure 10 shows that politics is another vital challenge of Nigerian industries while placing an order. Political insecurity should be brought to minimum as regard placing an order in Nigerian industries so that its economy can progress.

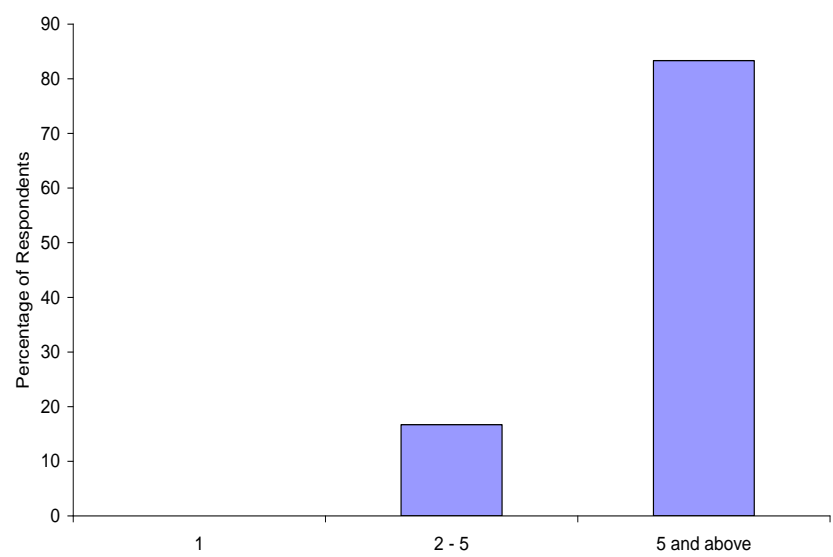

Fig 6: Chart for suppliers of raw materials

The frequency of order in Nigeria industries from Figure 11 shows that orders are affected by irregular lead time as to a percentage of 43.48. Lead-time is the period between the time an order is placed and the time the order is received. Inconsistent lead time causes increased in price of products and can equally causes demand rate to be increased. Another problem affecting receiving an order is transportation problem. This can be overcome by ensuring that our roads are good both in urban and rural areas. Availability of vehicle spare parts at affordable prices will also improve the situation. Another pragmatic approach is to ensure the production of raw materials within the industrial system in the future.

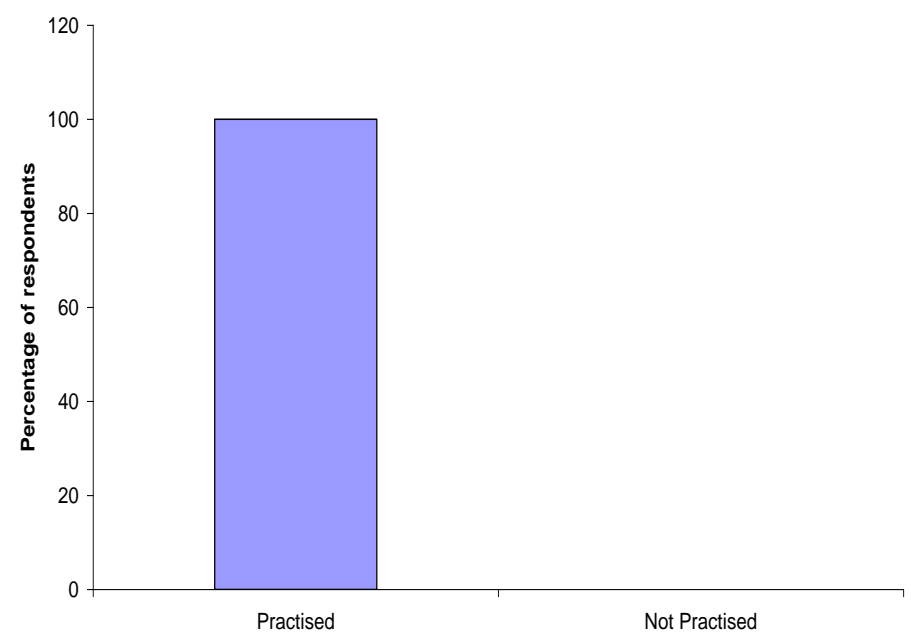

Fig 7: Chart for order of raw material 


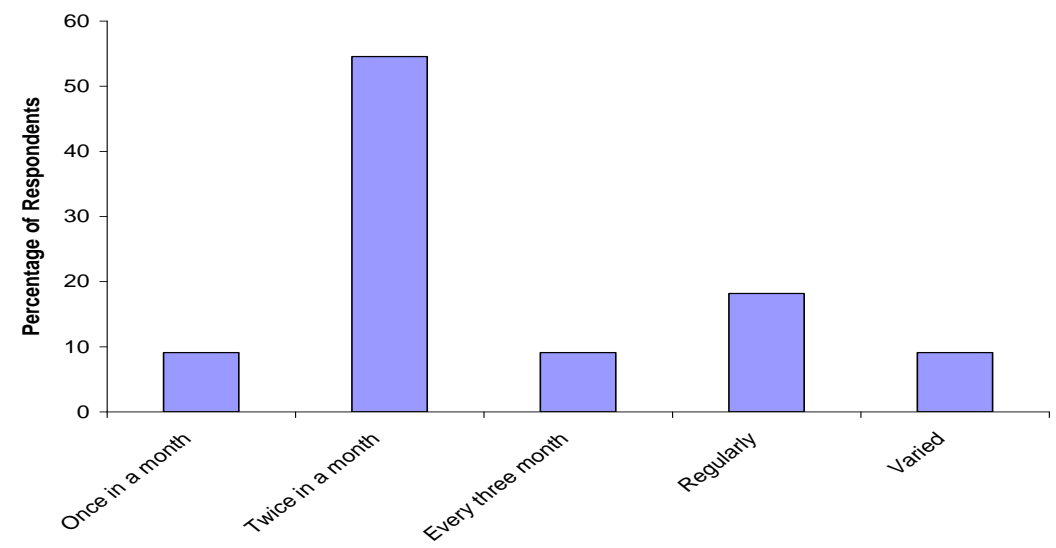

Fig 8: Frequency of ordering of raw materials

Under normal condition, the margin between demand rate and production rate should not be too large. If possible, demand rate should be equal to production rate. About $41.67 \%$ of Nigerian industries are performing well when it comes to checking the demand rate of their product while $16.67 \%$ of industries in Nigeria are their products being demanded averagely by customers (Figure 12). About one third (33.33\%) of industries in Nigeria have their products poorly demanded by customers. The reason for this low demand rate is not known. However, quality is suspected to influence the demand rate of the products. Meagre fund will be expended on inventory if the products attract more customers.

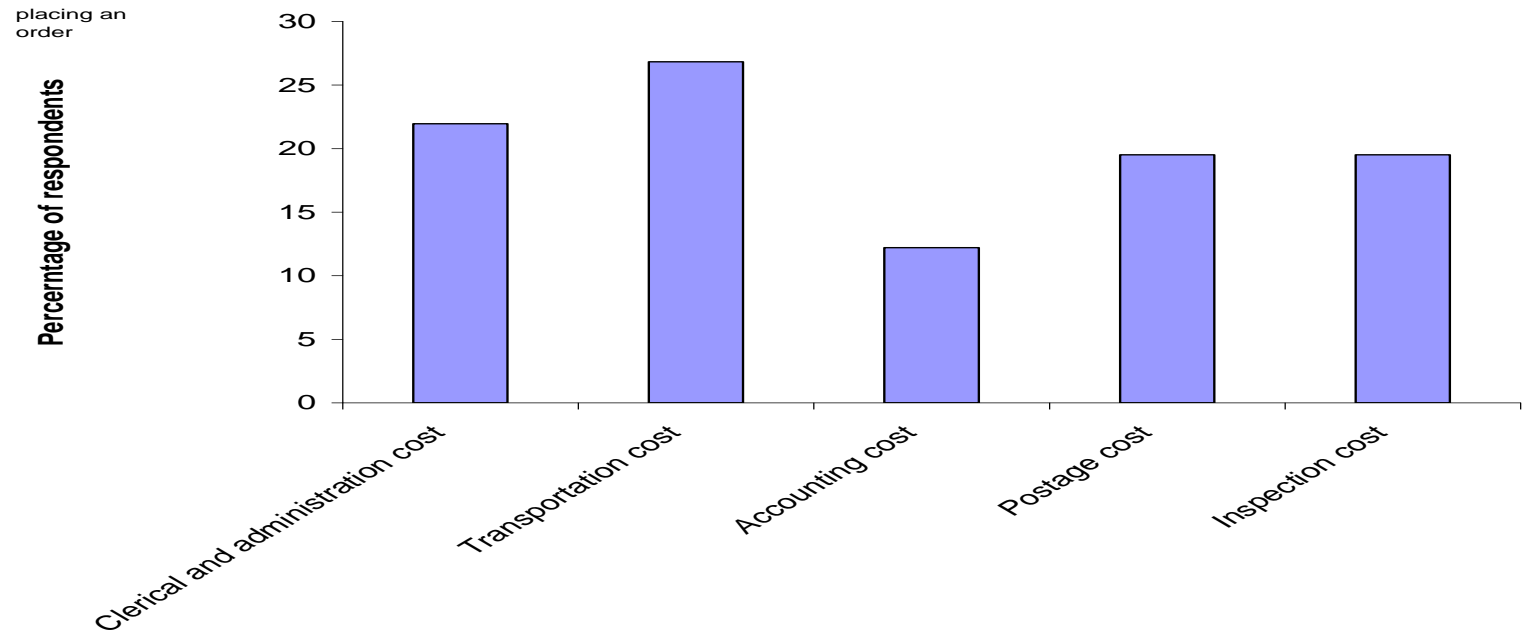

Fig 9: Costs associated with placing an order

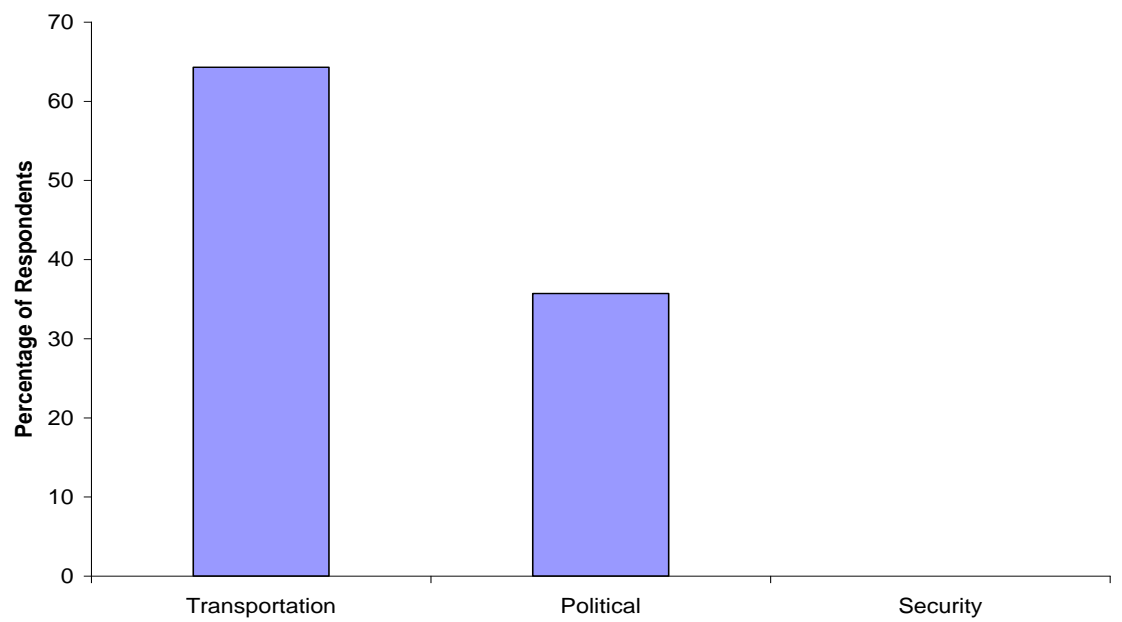

Fig 10: Problems encountered while placing an order 


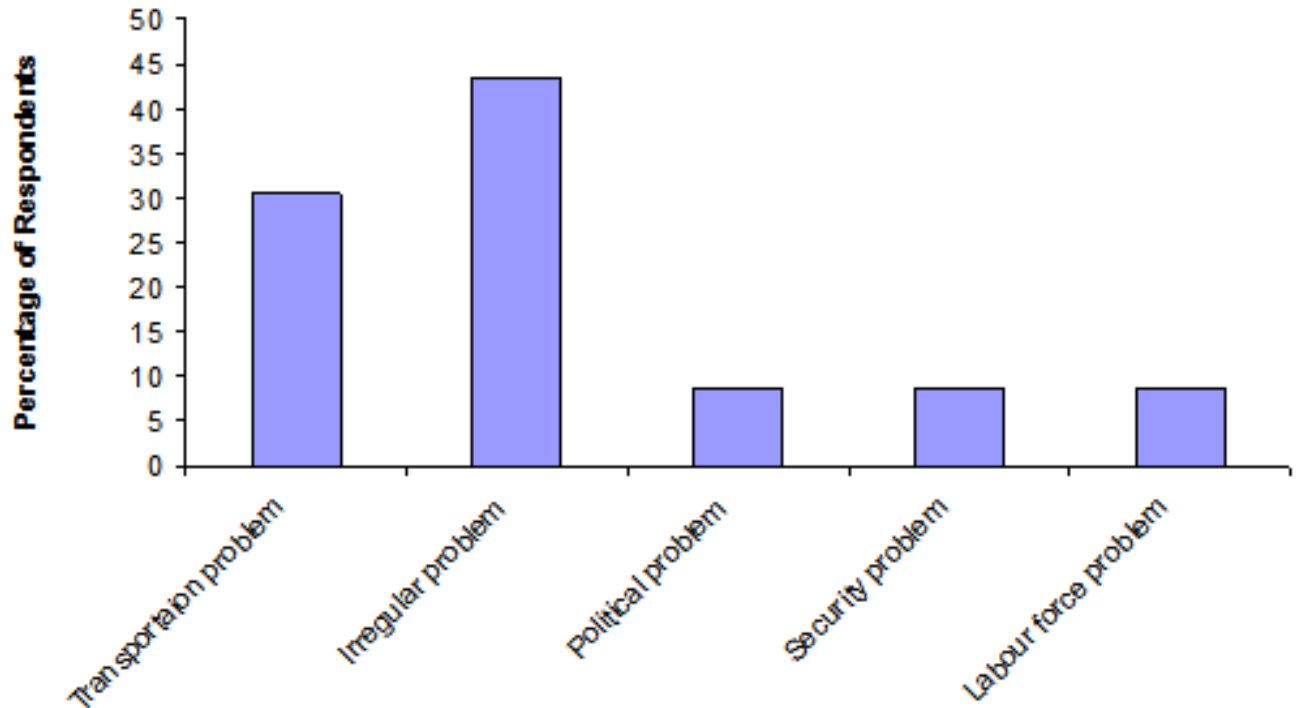

Fig 11: Problems encountered while receiving an order

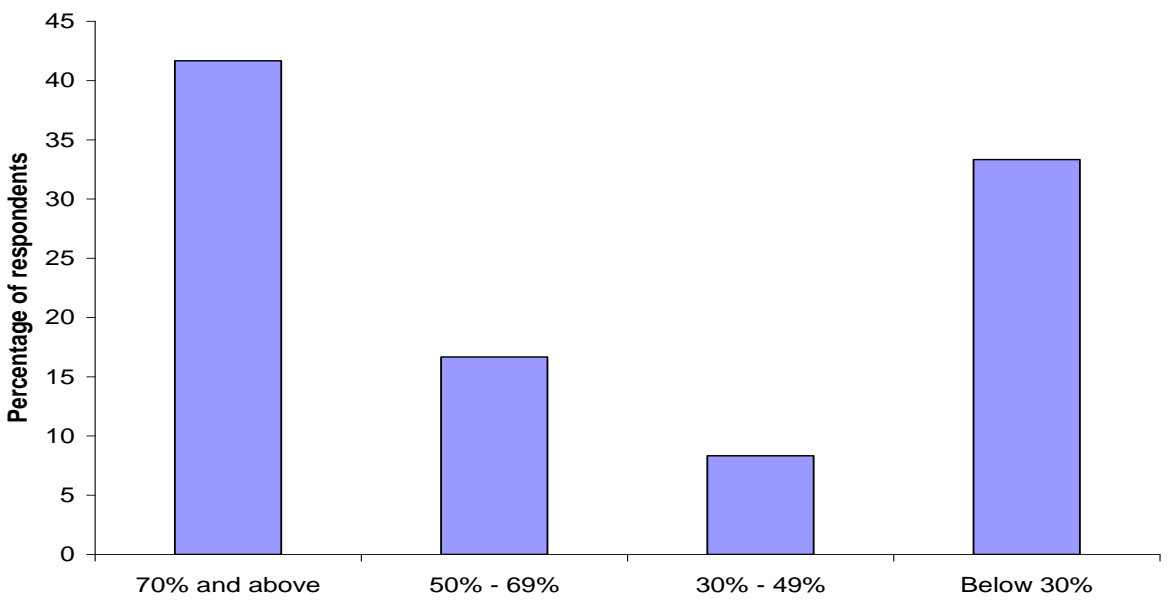

Fig 12: Product demand rate

Production rate was one of the options that were considered in the questionnaires. About $33.33 \%$ of Nigerian industries are producing above $70 \%$ of the intended production capacity. This is an excellent performance. Also, the histogram for production rate shows that $33.33 \%$ of industries in Nigeria are producing averagely $(50 \%-69 \%)$ while about $25 \%$ of industries are producing below $30 \%$. This poor performance in industries is attributed to some factors including low working capital, irregular lead-time, and political instability (Figure 13).

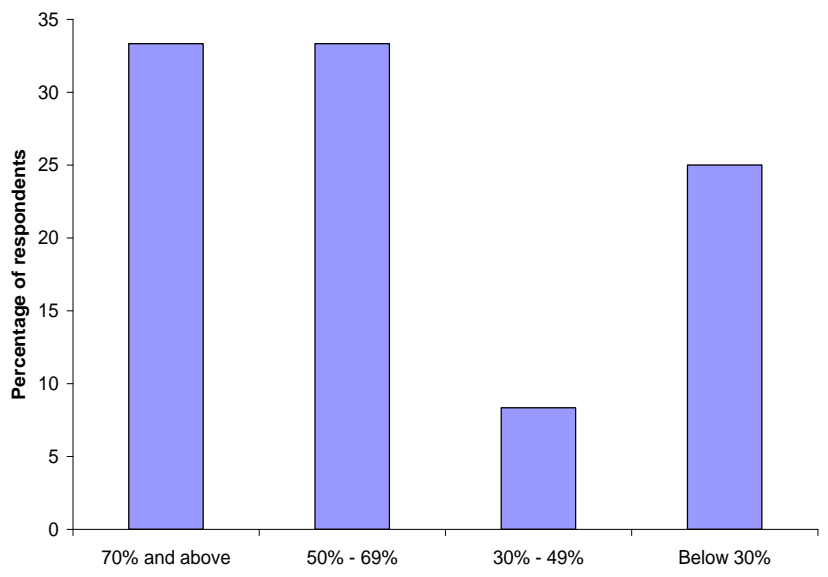

Fig 13: Production output rate 


\section{CONCLUSION}

Most of the industries in Nigeria are medium scaled private industries which employed more than 100 labours both skilled and unskilled labours. This contributes to economy and manpower development of the country. Most of these industries engaged in raw materials inventory system with more than 5 suppliers of raw materials which improved the quality of their goods and services. There is high level of insecurity in Nigerian industries as regards transportation of raw material, finished goods, low capital outlay, expatriates, among others; this insecurity has affected inventory management of the industries greatly. Other social challenges including political instability should be controlled and brought to minimal for the enhancement of a sustainable inventory management of the industries in the nearest future. Practical approaches such as just-in-time inventory system or expansion of number of suppliers of basic items (raw material, manpower, etc.) will be helpful in solving many of the inventory management challenges in the nearest future. The general finding from the results indicated that the size, funding capability, and operation environment of the individual industry played a significant role on the choice of inventory system it practiced.

\section{ACKNOWLEDGEMENT}

The Author acknowledged the Management of the Federal University of Technology, Akure, Nigeria for providing the facilities used for this study.

\section{REFERENCES}

[1] E.S. Buffa, Operations management ( USA: John Wiley and Sons Inc., 1972)

[2] W.H. Ford, Storage and stock control (USA: M.H publishing company, 1995)

[3] L.B. John, Marketing and purchasing (England: Paddington, 1979)

[4] O.D. Levis, Scientific inventory control (USA: Heinemann, 1976)

[5] W.P. George, Production and inventory control principles and techniques (India: Prentice- Hall International, 1985)

[6] A. Clark, H. Scarf, Operation policies for a multi-echelon inventory problem, Manag. Sci, 6, 1960, 475490.

[7] S.K. Goyal, Determination of optional packaging frequency of items jointly replenished, Manag. Sci., 2, 1974, 278-283.

[8] J.L. Balintfy, On a basis class of multi-items inventory problems. Manag. Sci., 10, 1964, 287-297

[9] E.A. Silver, A control system for coordinated inventory replenishment, Inter. J. of Prod Res., 12, 1974, 647-671.

[10] E. Ignall, Optional continuous review policies for two products inventory problems systems with joint setup costs. Manag. Sci, 15, 1969, 278-283.

[11] B. Kareem, Assessment of inventory control practices in Nigeria Industries, Res. Jour of App. Sci, 2(9), 2007, 947-952.

[12] O.G. Akanbi, A.E. Oluleye, M.A. Onanuga, Inventory model for deteriorating items with inflationary factors, Nig. J. of Eng. Manag. 2, 2001, 28-34..

[13] A. Chikan, E. Kovacs, T. Tatrai, (2005). Macroeconomics characteristics and inventory investment: a multi-country study, Proceedings of the $12^{\text {th }}$ Inter. Symp. on Inventories, Int. J. Prod. Econ., 2005, pp. $41-57$

[14] M. Ghali, Measuring the convexity of the cost functions, Proceedings of the $12^{\text {th }}$ Inter. Sympo. on Inventories, Int. J. Prod. Econ., 2004, pp. 130-147

[15] G. Zotteri, M. Kalchschmidt, F. Caniato, The impact of aggregation level on forecasting performance, Proceedings of the $12^{\text {th }}$ Inter. Sympo. on Inventories, Int. J. Prod. Econ., 2004, pp. 201-216.

[16] H.A. Taha, (2002). Operations research: an Introduction, (Singapore: Pearson Education Inc., 2008)

[17] R. Warren, W. Raymond, (1988). Need for inventory control (USA: Heinemann, 1988)

[18] R.E. Wildeman,J.B.G. Frenk, R. Dekker, An efficient optional solution Method for the joint replenishment problem, Eur. J. of Oper. Res., 99, 1997, 433- 444. 